\title{
A mixture containing galactooligosaccharide, produced by the enzymic activity of Bifidobacterium bifidum, reduces Salmonella enterica serovar Typhimurium infection in mice
}

\begin{abstract}
Correspondence
Laura E. J. Searle

I.searle@vla.defra.gsi.gov.uk
\end{abstract}

Received 23 June 2008

Accepted 22 September 2008

\author{
Laura E. J. Searle, ${ }^{1}$ Angus Best, ${ }^{1}$ Alejandro Nunez, ${ }^{1}$ \\ Francisco J. Salguero, ${ }^{1}$ Linda Johnson, ${ }^{1}$ Ute Weyer, ${ }^{1}$
}

Alexandra H. Dugdale, ${ }^{2}$ William A. Cooley, ${ }^{1}$ Ben Carter, ${ }^{3}$ Gareth Jones, ${ }^{1}$ George Tzortzis, ${ }^{4}$ Martin J. Woodward ${ }^{1}$ and Roberto M. La Ragione ${ }^{1}$

\author{
${ }^{1}$ Veterinary Laboratories Agency (VLA), Weybridge, Woodham Lane, New Haw, Addlestone, Surrey \\ KT15 3NB, UK \\ ${ }^{2}$ Faculty of Veterinary Science, University of Liverpool, Leahurst, Chester High Road, Neston, Wirral \\ CH64 7TE, UK \\ ${ }^{3}$ South East Wales Trials Unit, School of Medicine, Cardiff University, Cardiff CF14 4XN, UK \\ ${ }^{4}$ Clasado Ltd, 5 Canon Harnett Court, Wolverton Mill, Milton Keynes MK12 5NF, UK
}

The prebiotic Bimuno ${ }^{\mathbb{R}}$ is a mixture containing galactooligosaccharide, produced by the galactosyltransferase activity of Bifidobacterium bifidum NCIMB 41171 in the presence of lactose. Previous studies have implicated prebiotics in reducing infections by enteric pathogens, thus it was hypothesized that Bimuno ${ }^{\circledR}$ may confer some protection in the murine host from Salmonella enterica serovar Typhimurium (S. Typhimurium) infection. In this study, infection caused by S. Typhimurium SL1344nal ${ }^{r}$ in the presence or absence of Bimuno ${ }^{\circledR}$ was assessed using tissue culture assays, a murine ligated ileal gut loop model and a murine oral challenge model. In tissue culture adherence and invasion assays with HT-29-16E cells, the presence of $\sim 2 \mathrm{mM}$ Bimuno ${ }^{\mathbb{R}}$ significantly reduced the invasion of $S$. Typhimurium SL1344nal $(P<0.0001)$. In the murine ligated ileal gut loops, the presence of Bimuno ${ }^{\circledR}$ prevented colonization and the associated pathology of $S$. Typhimurium. In the BALB/c mouse model, the oral delivery of Bimuno ${ }^{\circledR}$ prior to challenge with $S$. Typhimurium resulted in significant reductions in colonization in the five organs sampled, with highly significant reductions being observed in the spleen at 72 and $96 \mathrm{~h}$ post-challenge $(P=0.0002,<0.0001$, respectively). Collectively, the results indicate that Bimuno ${ }^{\mathbb{R}}$ significantly reduced the colonization and pathology associated with $S$. Typhimurium infection in a murine model system, possibly by reducing the invasion of the pathogen into host cells.

\section{INTRODUCTION}

Salmonella enterica serovar Typhimurium (S. Typhimurium) is a zoonotic enteropathogen of increasing concern for human health (Meyerholz et al., 2002). S. Typhimurium is a common inhabitant of the intestines of farm animal species although it often causes significant morbidity and occasionally mortality in young susceptible animals (Carlson et al., 2002). Humans acquire infection through contact with infected animals or their products (Hald, 2001) and the infections in humans and animals

Abbreviations: GOS, galactooligosaccharide; HE, haematoxylin and eosin; VLA, Veterinary Laboratories Agency. constitute a major public health and economic burden (WHO, 2005). The ban on antibiotics as growth promoters in the European Union in 2006 (Castanon, 2007), and the emergence of antibiotic resistance (Carlson et al., 2002) in Salmonella spp., has led to the urgent requirement for alternative control strategies.

One such alternative to antibiotics as growth promoters is the use of prebiotics. Prebiotics are defined as nondigestible food ingredients that beneficially affect the host by selectively stimulating the growth and/or activity of one or a limited number of bacteria in the colon (Gibson \& Roberfroid, 1995). Prebiotics have been indicated to be utilized by health-promoting bacteria such as lactic acid 
bacteria in the colon (Gibson \& Roberfroid, 1995; Collins \& Gibson, 1999) and are implicated in conferring health benefits to the host. Previous studies have demonstrated that diets enriched with prebiotics, such as galactooligosaccharide (GOS), increase the number of bifidobacteria and/or lactobacilli, and/or their fermentation products, in the colon (Sako et al., 1999; Rabiu et al., 2001; Tzortzis et al., 2005b; Depeint et al., 2008). Short-chain fatty acids are the predominant fermentation products and have been implicated in calcium, magnesium and water absorption. Furthermore, it has been suggested that they provide energy to the colonic epithelium, increase epithelial cell growth (Sako et al., 1999; Tzortzis et al., 2005b) and suppress putrefying bacteria (Ito et al., 1997). Moreover, glycoconjugates containing GOS and other oligosaccharides have been implicated in the interactions between epithelial and bacterial cells (Schnaar, 1991; Tzortzis et al., 2005b), implying that these compounds also have the capacity to directly inhibit the attachment of pathogens to host cell surfaces by acting as competitive receptors (Arslanoglu et al., 2007). Many intestinal pathogens utilize short-chain oligosaccharides as receptors, thus the addition of prebiotics to a diet may have an anti-adhesive effect in the host (Gibson et al., 2005).

Among the various oligosaccharides tested as potential prebiotics, GOSs have attracted considerable interest (Tzortzis et al., 2005b), partly because they are natural compounds found in human breast milk and have been shown to be associated with improved colonic health in breast-fed infants (Sako et al., 1999; Boehm et al., 2004; Coppa et al., 2004).

The aim of the work described here was to evaluate the efficacy of the prebiotic Bimuno ${ }^{\circledR}$, a mixture containing GOS, produced by the galactosyltransferase activity of Bifidobacterium bifidum NCIMB 41171 in the presence of lactose, in mitigating against the adhesion and invasion of $S$. Typhimurium using appropriate in vitro and in vivo models, including tissue culture assays, a murine ligated ileal gut loop model and a murine oral challenge model of salmonellosis.

\section{METHODS}

\section{Bacterial strains and inocula}

Bacteria. Two well-characterized $S$. Typhimurium isolates were used throughout this study, strain LT2 and a nalidixic acid resistant derivative of SL1344, SL1344nal ${ }^{\mathrm{r}}$; the latter was used to allow selective recovery for bacterial enumeration during murine oral challenge studies. Escherichia coli $\mathrm{DH} 5 \alpha, \mathrm{K}-12$ (Gibco) was used as a negative control for bacterial invasion in adhesion and invasion assays. All isolates were obtained from the Veterinary Laboratories Agency (VLA, Weybridge, UK) culture collection and were maintained in heart infusion broth (HIB) $+30 \%$ glycerol (Oxoid) at $-80{ }^{\circ} \mathrm{C}$.

For all studies, bacterial isolates were cultured for $16 \mathrm{~h}$ aerobically at $37{ }^{\circ} \mathrm{C}$ with agitation (225 r.p.m.) in Luria-Bertani (LB-G) broth $(20 \mathrm{ml})$ (Oxoid). Subsequently, they were centrifuged at 4000 r.p.m. for $10 \mathrm{~min}$ to pellet the bacteria and resuspended to yield the specified concentration of bacteria (see below).

For tissue culture assays, SL1344nal ${ }^{\mathrm{r}}$, LT2 and K-12 were resuspended in inoculation fluid to yield a final concentration of $5 \times 10^{7}$ c.f.u. $\mathrm{ml}^{-1}$. In the murine ligated ileal gut loop experiment, SL1344nal ${ }^{\mathrm{r}}$ and LT2 were resuspended in pre-warmed PBS (0.1 M PBS, pH 7.2) to yield a final concentration of $1 \times 10^{9}$ c.f.u. in a $100 \mu$ l volume per loop. Similarly, for the murine oral challenge model, SL1344nal ${ }^{\mathrm{r}}$ was resuspended in $0.1 \mathrm{M}$ PBS to yield a final concentration of $1 \times 10^{8}$ c.f.u. $\mathrm{ml}^{-1}$.

Test substance - Bimuno ${ }^{\circledR}$. The GOS mixture, Bimuno ${ }^{\circledR}$, used in this study was produced from the activity of galactosyltransferases from B. bifidum NCIMB 41171 in the presence of lactose (Tzortzis et al., 2005a, b). It has been shown to consist of GOSs in mainly the $\beta 1-$ $3, \beta 1-4$ and $\beta 1-6$ linkages, as well as a dissacharide fraction of $\alpha 1-6$ galactobiose (Tzortzis et al., 2005b; Depeint et al., 2008). The estimated $M_{\mathrm{r}}$ of this prebiotic mixture is $\sim 2546.6$.

Tissue culture adhesion and invasion studies. Human colonic cells, HT-29-19A (non-mucus-secreting) and HT-29-16E (mucussecreting), were seeded at $2 \times 10^{5}$ cells $\mathrm{ml}^{-1}$ and cultured using standard procedures with Dulbecco's Modified Eagle's Medium (DMEM; Sigma-Aldrich) supplemented with fetal calf serum (10\%), $100 \times$ non-essential amino acids $(1 \%), 2 \mathrm{mM}$ L-glutamine and gentamicin $\left(50 \mu \mathrm{g} \mathrm{ml}^{-1}\right)$ (Sigma-Aldrich). Five-day-old monolayers were washed twice with Hanks' balanced salts solution (HBSS; SigmaAldrich) to remove cell debris and residual gentamicin. The bacterial inoculum was resuspended in incomplete Dulbecco's medium (without antibiotics or fetal calf serum) and delivered in $1 \mathrm{ml}$ volumes to each well $\left(5 \times 10^{7}\right.$ c.f.u. $\left.\mathrm{ml}^{-1}\right)$. Inocula were prepared with and without $\sim 2 \mathrm{mM}$ Bimuno ${ }^{\mathbb{R}}$ (approx. $5 \mathrm{mg} \mathrm{m}^{-1}$ ). Approximate values are stated as GOS is a complex mixture of oligosaccharides and therefore mean values were used to calculate the estimated $M_{\mathrm{r}}$.

The plates were incubated at $37{ }^{\circ} \mathrm{C}$ (in the presence of $5 \% \mathrm{CO}_{2}$ ) for $2 \mathrm{~h}$. To count the number of bacteria associated with the cells, the cells were washed three times with HBSS and disrupted with $1 \%$ Triton X-100 (Sigma-Aldrich) and mechanical stirring. To differentiate the number of bacteria that had invaded, $100 \mu \mathrm{g} \mathrm{ml}^{-1}$ gentamicin solution (Sigma-Aldrich) was added to incomplete DMEM, delivered to each well and incubated for a further $2 \mathrm{~h}$. The cells were subsequently washed three times in HBSS and disrupted as described above. For bacterial enumeration, samples were 10-fold serially diluted, $10^{-1}-10^{-4}$ for the association assays and $10^{0}-10^{-3}$ for the invasion assays. Diluted samples were plated onto LB-G agar (Oxoid) and incubated for $16 \mathrm{~h}$ at $37^{\circ} \mathrm{C}$. This experiment was repeated using $\sim 20 \mathrm{mM}$ Bimuno ${ }^{\mathbb{R}}$ and all assays were conducted in triplicate.

Murine ligated ileal gut loop studies. Murine ligated ileal gut loop studies were performed essentially as described previously (Girard $e t$ al., 2008), with minor modifications. Four 8-week-old female SLC: ICR mice (VLA, colony) were used for these studies. The ileal gut loops were inoculated with $100 \mu \mathrm{l}\left(1 \times 10^{9}\right.$ c.f.u. $)$ of test bacteria with or without Bimuno ${ }^{\circledR}(2 \mathrm{mM})$ by transmural injection. Control loops were inoculated with $100 \mu \mathrm{l}$ sterile PBS or Bimuno ${ }^{\mathbb{B}}$ alone. Following an incubation period of $30 \mathrm{~min}$, the loops were harvested under terminal anaesthesia and then the mouse was euthanized with intra-cardiac barbiturate (Somulose; Arnolds) overdose. Harvested tissues were fixed immediately for electron microscopy and histopathology analysis, as described below. The studies were conducted with two S. Typhimurium isolates, SL1344nal ${ }^{\mathrm{r}}$ and LT2.

All animal studies were approved by the local ethics committee and conducted under the jurisdiction of the home office licence 70/6103 in accordance with the Animals (Scientific Procedures) Act 1986. 


\section{Pathological studies}

Light microscopy. For light microscopy, samples of liver, spleen, ileum, caecum and colon were collected into $10 \%$ neutral buffered formalin at ambient temperature and left to fix for a minimum of $24 \mathrm{~h}$. Trimmed tissues were processed routinely in paraffin wax, $4 \mu \mathrm{m}$ sections were stained with haematoxylin and eosin (HE) and samples were examined using a Leica DMLB light microscope (Leica Microsystems) and photographed using a Leica DFC320 digital camera (Leica Microsystems). Tissues were evaluated microscopically for histopathological changes and were scored subjectively with regard to: lymphoid hyperplasia, submucosal oedema, portal inflammation and pyogranuloma formation. For the principles of evaluation between groups in this report, two histological characteristics were reported. Firstly, tissues appeared normal, within a normal level of variation in comparison to controls; and, secondly, the appearance of pyogranulomas. The latter is defined as foci of neutrophils, macrophages and necrosis.

Electron microscopy. Glutaraldehyde fixed tissues were sectioned to 1-2 $\mathrm{mm}$ in thickness at sites where lesions were identified during microscopical examinations of the HE sections. These were processed for transmission electron microscopy as described previously (La Ragione et al., 2006) and were analysed using a Philips CM10 transmission electron microscope.

\section{Murine oral challenge studies}

Trial 1 - scoping experiment. Thirty 5 -week-old female BALB/c (Charles River) mice were divided randomly into two (A, B) equal groups (15 mice per cage) and housed with food and water ad libitum for 1 week prior to inoculation. The 15 mice in group A were dosed

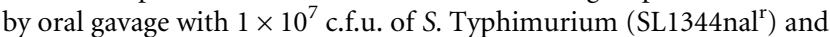
group B were dosed with $2500 \mathrm{mg}$ Bimuno ${ }^{\mathbb{R}} \mathrm{kg}^{-1} \sim 30 \mathrm{~min}$ prior to challenge with $S$. Typhimurium (SL1344nal ${ }^{\mathrm{r}}$ ) by oral gavage.

Approximately $24 \mathrm{~h}$ post-challenge and at $24 \mathrm{~h}$ intervals thereafter, 20 faecal pellets were collected from each group. Briefly, the mice were transferred to a sterile container and after $\sim 25$ min faecal samples were collected. Faeces from each group were weighed, homogenized in $9 \mathrm{ml}$ selenite broth (Oxoid) and subsequently 10-fold serially diluted $\left(10^{-1}-10^{-4}\right)$. Each dilution was plated onto brilliant green agar (BGA; Oxoid) supplemented with $15 \mu \mathrm{g}$ nalidixic acid $\mathrm{ml}^{-1}$ (Sigma-Aldrich). Additionally, at 24,72 and $96 \mathrm{~h}$ post-inoculation, five mice from each group were selected randomly and euthanased by cervical dislocation. At necropsy, liver, spleen, ileum, caecum, colon and heart blood were sampled aseptically. Where possible, $1 \mathrm{~g}$ tissue was placed in $9 \mathrm{ml}$ selenite broth for bacteriology. Specifically, the tissues were homogenized, 10 -fold serially diluted $\left(10^{-1}-10^{-4}\right)$, plated onto BGA (supplemented with $15 \mu \mathrm{g}$ nalidixic acid $\mathrm{ml}^{-1}$ ) and incubated at $37^{\circ} \mathrm{C}$ for $16 \mathrm{~h}$ for bacterial enumeration of $S$. Typhimurium SL1344nal ${ }^{\mathrm{r}}$. All tissues and pooled faecal pellets were enriched in selenite broth at $37{ }^{\circ} \mathrm{C}$. At $24 \mathrm{~h}$ post-enrichment, a $100 \mu \mathrm{l}$ aliquot was taken from the enriched samples of all tissue and faecal samples that were negative upon direct plating. This sample was spread-plated onto BGA (supplemented with $15 \mu \mathrm{g}$ nalidixic acid $\mathrm{ml}^{-1}$ ), and if negative for growth, a $100 \mu \mathrm{l}$ aliquot was taken at day 7 and plated as described above.

Trial two. One hundred and twenty female BALB/c mice were divided randomly into four (C-F) equal treatment groups of 30 but distributed as 15 mice per cage. Groups were dosed by oral gavage as follows: group C received sterile PBS; group D was inoculated with $2500 \mathrm{mg}$ Bimuno ${ }^{\circledR} \mathrm{kg}^{-1}$; group $\mathrm{E}$ was dosed with $1 \times 10^{7}$ c.f.u. $S$. Typhimurium (SL1344nal ${ }^{\mathrm{r}}$ ); and group $\mathrm{F}$ was inoculated with $2500 \mathrm{mg}$ Bimuno ${ }^{\circledR} \mathrm{kg}^{-1} \sim 30 \mathrm{~min}$ prior to being challenged with $1 \times 10^{7}$ c.f.u. S. Typhimurium. Necropsies were conducted on five randomly selected mice per group at $4,8,24,72,96$ and 120 h postinoculation, and samples were collected and processed as described previously.

\section{Statistical analyses}

In vitro studies. Plots were calculated after transforming data onto the $\log _{2}$ scale. A general linear model was fitted to the $\log _{2}$ (count) data and the terms included in the model were the treatment (Salmonella, Salmonella with Bimuno ${ }^{\circledR}$, and Bimuno ${ }^{\circledR}$ before Salmonella), mucus $(-/+)$ HT-29 cell type, and strain (LT2, SL1344nal $\left.{ }^{\mathrm{r}}, \mathrm{K}-12\right)$. Comparisons were made of the differences between the strains in the two cell types, and the differences induced by the treatment regime on the isolates. The results from the strain-by treatment were adjusted for multiple testing by Dunnett's test and the pairwise comparisons were GP/G- (where the delivery of Bimuno ${ }^{\mathbb{R}}$ before the isolate was compared to times where no Bimuno ${ }^{\mathbb{R}}$ was present) and GT/G- (where the delivery of Bimuno ${ }^{\mathbb{R}}$ at the same time as the isolate was compared to times where no Bimuno ${ }^{\mathbb{B}}$ was present) for both infection types. All comparisons were based on $95 \%$ confidence intervals on the $\log _{2}$ scale and back-transformed onto the raw scale with their associated $P$-value (given to four decimal places) and $95 \%$ confidence intervals calculated.

In vivo studies. Plots were calculated after transforming data onto the $\log _{2}$ scale. A general linear model was used to model the $\log _{2}$ (count) data. The model fitted terms for time point, strain and an interaction between time point and strain, for each measurement location separately. The geometric mean difference was calculated and significant differences at the $5 \%$ level were used to ascertain evidence of a difference. The $95 \%$ confidence intervals were calculated for the geometric mean differences between dosing with Salmonella alone and dosing with Bimuno ${ }^{\circledR}$ before Salmonella (based on a $\log _{2}$ scale). The differences were obtained for each measurement location and time point and were back-transformed [Salmonella (Bimuno ${ }^{\circledR}$ prior to Salmonella)]. P-values were given to four decimal places.

\section{RESULTS}

\section{In vitro tissue culture assays}

Human colonic cell lines were infected with $S$. Typhimurium and E. coli in the presence or absence of Bimuno ${ }^{\circledR}$. The addition of $2 \mathrm{mM}$ and $20 \mathrm{mM}$ Bimuno ${ }^{\circledR}$ significantly reduced the invasion of $S$. Typhimurium (Tables 1 and 2). Specifically, the invasion of $S$. Typhimurium SL1344nal ${ }^{\mathrm{r}}$ into HT-29-16E cells was significantly reduced when $2 \mathrm{mM}$ Bimuno ${ }^{\circledR}$ was added prior to or at the same time as the bacteria $(P<0.0001)$ (Table 1$)$. The invasion of $S$. Typhimurium LT2 was significantly reduced in both the HT-29-16E and HT-29-19A cell lines when $20 \mathrm{mM}$ Bimuno ${ }^{\mathbb{R}}$ was added at the same time as the bacterial inocula ( $P=0.0314,0.0377$, respectively) (Table 2 ). The two concentrations of Bimuno ${ }^{\circledR}$ affected the invasiveness of the two Salmonella strains differently. There were no significant differences for the adhesion of SL1334nal ${ }^{\mathrm{r}}$, LT2 or K-12 to either cell type in the presence of $2 \mathrm{mM}$ Bimuno ${ }^{\mathbb{R}}$ (Table 1 ). Conversely, the adherence of $S$. Typhimurium SL1344nal ${ }^{\mathrm{r}}$ and LT2 was significantly increased in all experiments in which $20 \mathrm{mM}$ Bimuno ${ }^{\mathbb{R}}$ was applied at the same time as the bacteria; i.e. the application of $20 \mathrm{mM}$ Bimuno ${ }^{\circledR}$ with 
Table 1. Adherence and invasion of $S$. Typhimurium and $E$. coli to human colonic HT-29-16E (mucus-secreting) and HT-29-19A (non-mucus-secreting) cells in the presence or absence of $2 \mathrm{mM}$ Bimuno ${ }^{\circledR}$

Bold highlighting of data indicates significant results $(P<0.05)$.

\begin{tabular}{|c|c|c|c|c|c|}
\hline Cell line & Adherence/invasion & Condition & c.f.u. $\mathrm{ml}^{-1}$ & $P$-value & $\begin{array}{c}95 \% \text { confidence } \\
\text { intervals }\end{array}$ \\
\hline \multirow[t]{9}{*}{ HT-29-16E } & Adherence & $\mathrm{K}-12$ & $8.50 \times 10^{3}$ & & \\
\hline & & Bimuno ${ }^{\mathbb{R}}$ before $\mathrm{K}-12$ & $9.58 \times 10^{3}$ & 0.747 & $-1.42,1.58$ \\
\hline & & Bimuno ${ }^{\mathbb{R}}+\mathrm{K}-12$ & $1.04 \times 10^{4}$ & 0.9136 & $-2.74,0.26$ \\
\hline & & LT2 & $6.02 \times 10^{4}$ & & \\
\hline & & Bimuno ${ }^{\mathbb{R}}$ before LT2 & $2.88 \times 10^{4}$ & 0.1013 & $0.15,1.19$ \\
\hline & & Bimuno ${ }^{\circledR}+$ LT2 & $6.33 \times 10^{4}$ & 0.6321 & $0.28,2.20$ \\
\hline & & SL1344nal ${ }^{\mathrm{r}}$ & $1.95 \times 10^{4}$ & & \\
\hline & & Bimuno ${ }^{\circledR}$ before SL1344nal ${ }^{\mathrm{r}}$ & $2.75 \times 10^{4}$ & 0.2879 & $0.62,4.90$ \\
\hline & & Bimuno $^{\circledR}+$ SL1344nal ${ }^{\mathrm{r}}$ & $2.84 \times 10^{4}$ & 0.3954 & $0.55,4.38$ \\
\hline \multirow[t]{9}{*}{ HT-29-19A } & Adherence & $\mathrm{K}-12$ & $7.56 \times 10^{3}$ & & \\
\hline & & Bimuno $^{(\mathbb{R}}$ before $\mathrm{K}-12$ & $6.40 \times 10^{3}$ & 0.8156 & $-1.32,1.67$ \\
\hline & & Bimuno $^{\circledR}+\mathrm{K}-12$ & $8.00 \times 10^{3}$ & 0.6908 & $-1.20,1.79$ \\
\hline & & LT2 & $6.50 \times 10^{4}$ & & \\
\hline & & Bimuno ${ }^{\circledR}$ before LT2 & $2.75 \times 10^{4}$ & 0.1579 & $0.17,1.35$ \\
\hline & & Bimuno $^{\circledR}+$ LT2 & $5.08 \times 10^{4}$ & 0.9242 & $0.37,2.96$ \\
\hline & & SL1344nal ${ }^{\mathrm{r}}$ & $1.05 \times 10^{5}$ & & \\
\hline & & Bimuno $^{\circledR}$ before SL1344nal ${ }^{\mathrm{r}}$ & $1.82 \times 10^{5}$ & 0.5073 & $0.5,3.98$ \\
\hline & & Bimuno $^{\circledR}+$ SL1344nal ${ }^{\mathrm{r}}$ & $1.63 \times 10^{5}$ & 0.4681 & $0.52,4.11$ \\
\hline \multirow[t]{6}{*}{ HT-29-16E } & Invasion & LT2 & $2.66 \times 10^{3}$ & & \\
\hline & & Bimuno ${ }^{\mathbb{R}}$ before LT2 & $2.43 \times 10^{3}$ & 0.7617 & $0.54,1.58$ \\
\hline & & Bimuno ${ }^{\mathbb{R}}+$ LT2 & $2.44 \times 10^{3}$ & 0.7493 & $0.54,1.57$ \\
\hline & & SL1344nal ${ }^{\mathrm{r}}$ & $1.00 \times 10^{4}$ & & \\
\hline & & Bimuno ${ }^{\circledR}$ before SL1344nal ${ }^{\mathrm{r}}$ & $3.12 \times 10^{3}$ & $<0.0001$ & $0.18,0.53$ \\
\hline & & Bimuno $^{\mathbb{R}}+$ SL1344nal ${ }^{\mathrm{r}}$ & $2.44 \times 10^{3}$ & $<0.0001$ & $0.14,0.42$ \\
\hline \multirow[t]{6}{*}{ HT-29-19A } & Invasion & LT2 & $2.95 \times 10^{3}$ & & \\
\hline & & Bimuno ${ }^{\circledR}$ before LT2 & $4.04 \times 10^{3}$ & 0.2435 & $0.80,2.35$ \\
\hline & & Bimuno $^{\circledR}+$ LT2 & $4.32 \times 10^{3}$ & 0.1593 & $0.85,2.51$ \\
\hline & & SL1344nal ${ }^{\mathrm{r}}$ & $3.10 \times 10^{3}$ & & \\
\hline & & Bimuno ${ }^{\circledR}$ before SL1344nal ${ }^{\mathrm{r}}$ & $2.97 \times 10^{3}$ & 0.8738 & $0.56,1.64$ \\
\hline & & Bimuno $^{\circledR}+$ SL1344nal ${ }^{\mathrm{r}}$ & $3.05 \times 10^{3}$ & 0.9473 & $0.57,1.68$ \\
\hline
\end{tabular}

SL1344nal ${ }^{\mathrm{r}}$ significantly increased its adherence to HT-29-16E cells when compared to controls $(P<0.0001)$ (Table 2$)$. No cytopathic effects were observed after the application of Bimuno ${ }^{\circledR}$ to either type of HT-29 cells at either concentration.

\section{In vivo murine ligated ileal gut loop studies}

Macroscopic findings. Following removal from the animal, loops were of normal diameter and no differences were observed in the PBS, Bimuno ${ }^{\circledR}$ or Bimuno ${ }^{\circledR}+S$. Typhimurium inoculated loops with respect to wall colour, thickness and the appearance of the intestinal contents. However, loops inoculated with $S$. Typhimurium alone were hyperaemic, mildly oedematous on the serosal aspect and the contents were mucoid and blood-stained.

Histopathology. Transmural inoculation of Bimuno ${ }^{\circledR}$ into the ligated ileal intestinal loops did not induce any significant histopathological changes in the intestinal mucosa (when compared with control PBS inoculated loops) (Fig. 1A, B).
However, inoculation of S. Typhimurium strains SL1344nal ${ }^{\mathrm{r}}$ or LT2 into the loops resulted in a diffuse (multifocal) vacuolar degeneration and lytic necrosis of the enterocytes of the tip of the villi associated with bacterial attachment and invasion, erosion and ulceration of the epithelial layer and necrosis of the underlying lamina propria (Fig. 1C, E). No inflammatory changes or polymorphonuclear leukocyte infiltration bordering these areas were observed. In contrast, however, no morphological changes in the epithelium and mucosa were observed after the inoculation of Bimuno ${ }^{\circledR}$ at the same time as S. Typhimurium SL1344nal ${ }^{\mathrm{r}}$ or LT2 despite abundant numbers of bacteria being present in the intestinal lumen and occasional attachment to enterocytes (Fig. 1D, F).

Electron microscopy studies. All gut loop tissues sampled were processed for electron microscopy and those infected with either S. Typhimurium SL1344nal ${ }^{\mathrm{r}}$ or LT2 alone showed marked pathology, indicative of necrosis (Fig. 2). Bacteria were observed adhered to the epithelium and invading into 
Table 2. Adherence and invasion of $S$. Typhimurium and $E$. coli to human colonic HT-29-16E (mucus-secreting) and HT-29-19A (non-mucus-secreting) cells in the presence or absence of $20 \mathrm{mM}$ Bimuno ${ }^{\circledR}$

Bold highlighting of data indicates significant results $(P<0.05)$.

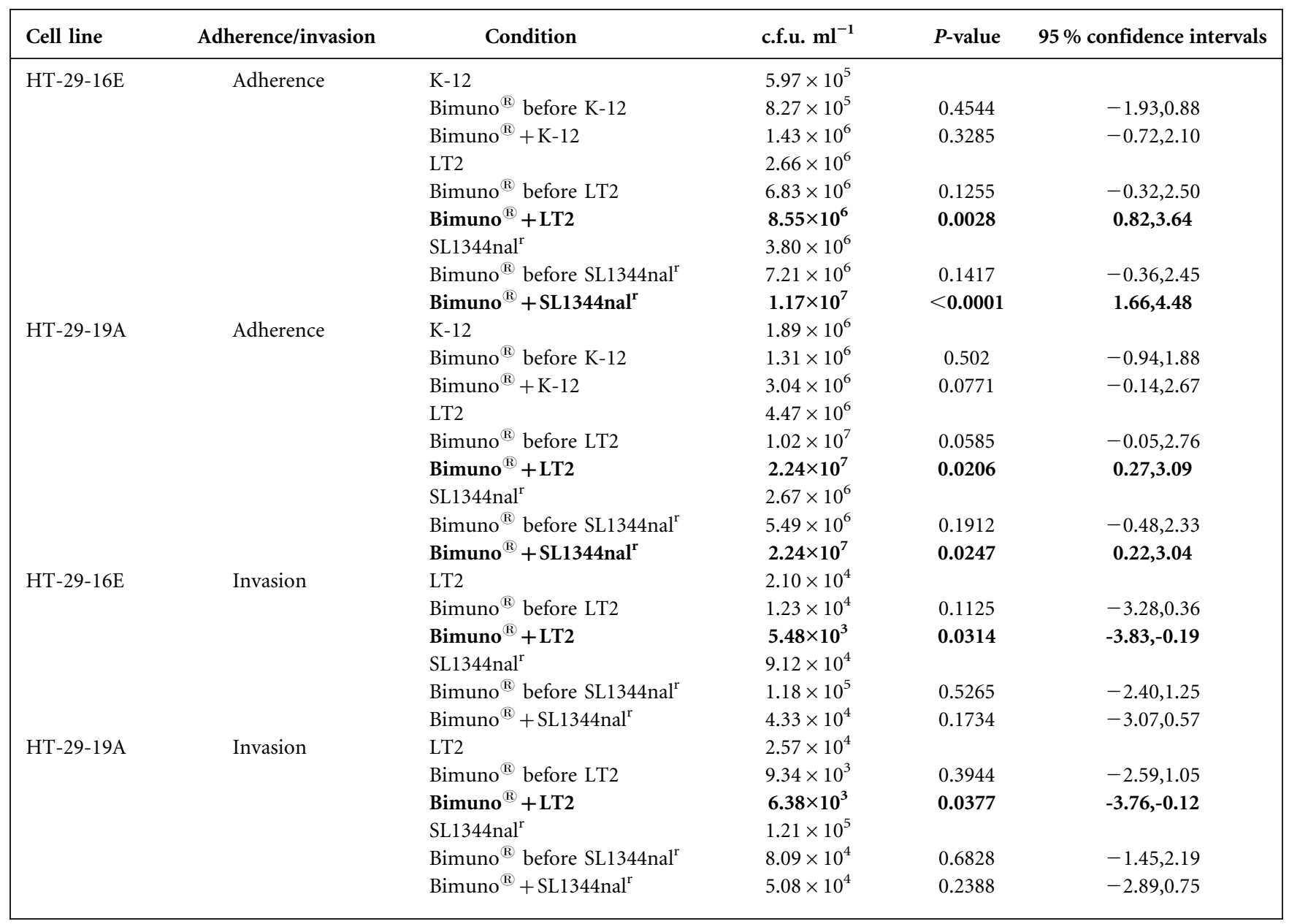

the enterocytes (Fig. 2C, E). Tissues examined from the PBS, Bimuno $^{\circledR}$ and Bimuno ${ }^{\circledR}$ with $S$. Typhimurium treatments showed no pathology and no evidence of bacterial adherence or invasion (Fig. 2A, B, D, F).

\section{In vivo oral challenge studies}

Murine oral challenge experiment: trial 1, scoping experiment. Clinical signs of murine salmonellosis such as ruffled fur, prostration and dehydration were only observed in those mice dosed with $S$. Typhimurium alone (group A) at $96 \mathrm{~h}$ post-challenge. Bacteriology was conducted on the organs sampled upon serial necropsy. Delivery of Bimuno ${ }^{\mathbb{R}}$ prior to challenge with $S$. Typhimurium SL1344nal ${ }^{\mathrm{r}}$ resulted in a general trend of reduced counts, significantly so at $72 \mathrm{~h}$ in the ileum $[P=0.0179 ; 95 \%$ CI $(1.34,13.36)]$.

\section{Murine oral challenge experiment: trial 2}

Clinical signs

All mice dosed with PBS, Bimuno ${ }^{\circledR}$ or Bimuno ${ }^{\circledR}$ prior to challenge with $S$. Typhimurium remained clinically normal throughout the study. All mice dosed with $S$. Typhimurium alone showed moderate clinical signs of murine salmonellosis at 96 and $120 \mathrm{~h}$ post-challenge.

Faecal shedding

At $24 \mathrm{~h}$ post-infection, shedding of $S$. Typhimurium was in the region of $10^{5}$ c.f.u. ( $\mathrm{g}$ faeces) ${ }^{-1}$ in both groups dosed with $S$. Typhimurium (groups E and F), and no significant differences in shedding were observed throughout the sampling period. However, by $120 \mathrm{~h}$ post-infection, a trend was observed where the level of $S$. Typhimurium SL1344nal ${ }^{\mathrm{r}}$ shed in the faeces of the group pre-dosed with Bimuno $^{\circledR}$ was reduced (by 2.5 logs).

Invasion of spleen and liver

As anticipated, S. Typhimurium SL1344nal ${ }^{\mathrm{r}}$ was not detected in the control groups that received PBS or Bimuno ${ }^{\circledR}$ alone. In the challenge groups, the numbers of $S$. Typhimurium in the spleen and liver samples of the group pre-dosed with Bimuno ${ }^{\mathbb{R}}$ (group F) were similar to or lower 
A

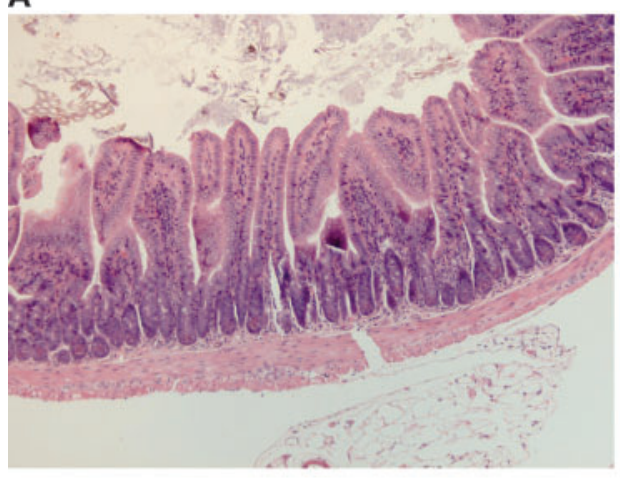

C

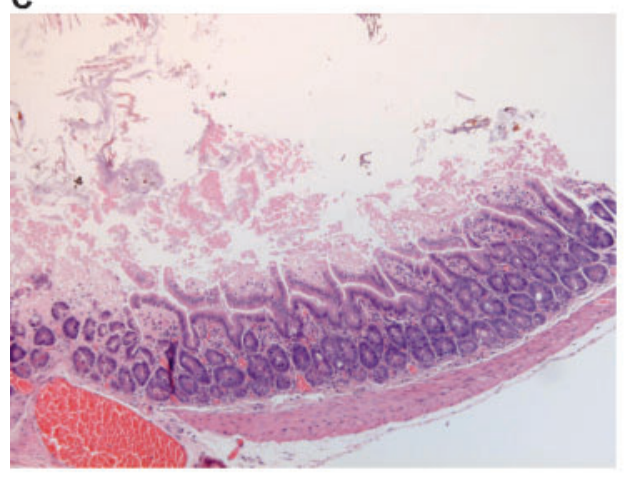

$E$

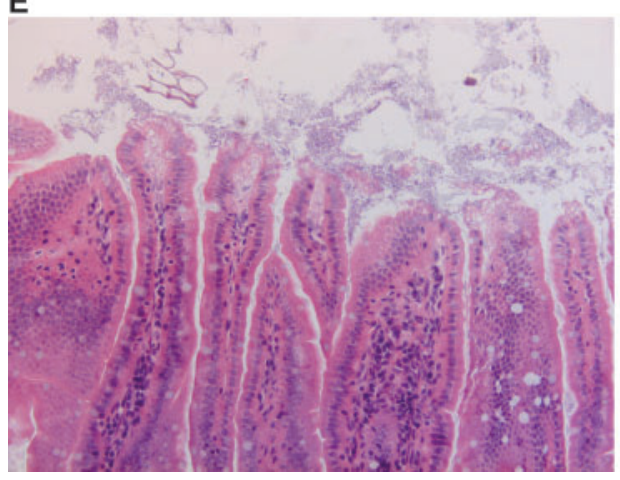

B

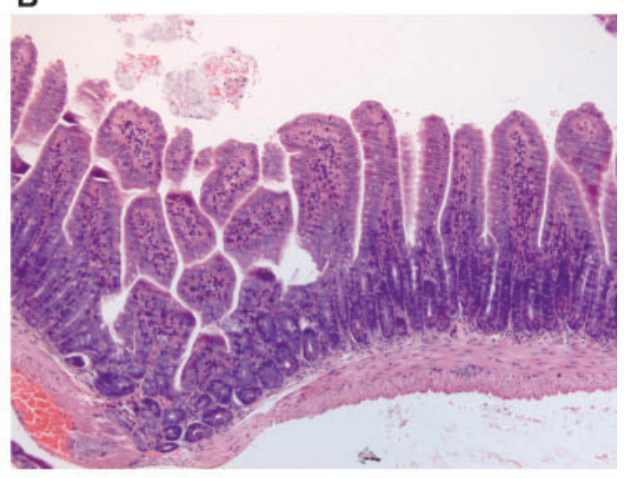

D

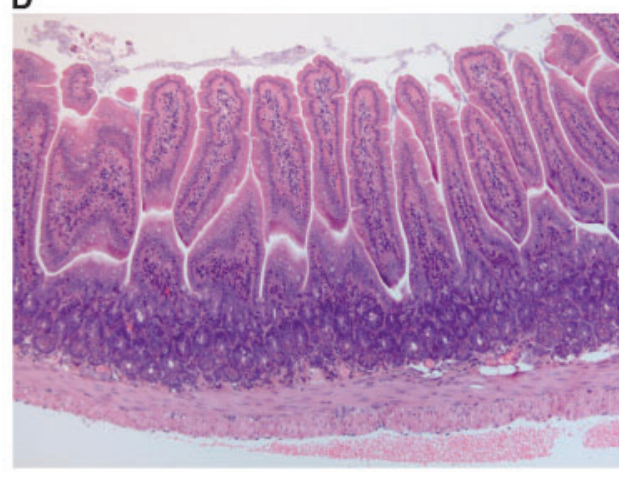

$\mathbf{F}$

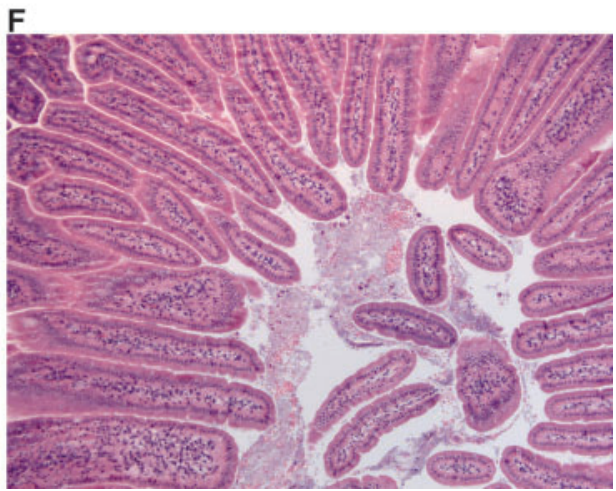

Fig. 1. Haematoxylin and eosin, histopathology of gut loops inoculated with PBS (A), Bimuno ${ }^{\mathbb{B}}$ (B), S. Typhimurium SL1344nal ${ }^{r}(C)$, SL1344nal ${ }^{r}$ with Bimuno ${ }^{\mathbb{B}}$ (D), S. Typhimurium LT2 (E) and LT2 with Bimuno ${ }^{\mathbb{B}}(\mathrm{F})$. All images are at $\times 100$ magnification. Note loops $A$ and $B$ show no pathology and normal tissue architecture. Loops $C$ and $E$ illustrate vacuolar degeneration and lytic necrosis of the enterocytes of the top of the villi. Loops $D$ and $F$ show no morphological changes to the epithelial structure and mucosa indicating a protective effect conferred by Bimuno ${ }^{\mathbb{R}}$.

than those of the group challenged with $S$. Typhimurium alone (group E) (Fig. 3a, b) at all time points. Unlike group E, $S$. Typhimurium was not recovered from the spleens of group $\mathrm{F}$ at 4,8 and $24 \mathrm{~h}$ and thereafter it was recovered in lower numbers (Fig. 3a). Significant reductions in $S$. Typhimurium colonization were observed in group $\mathrm{F}$ at 72 and $96 \mathrm{~h}$ post-challenge in both the spleen $[P=0.0002,95 \%$ CI $(-12.5,-4.17) ;<0.0001,95 \%$ CI $(-14.1,-5.31)]$ and liver $[P=0.0021,95 \% \mathrm{CI}(-12.3,-2.85)$; $0.0013,95 \% \mathrm{CI}$ $(-13.4,-3.43)]$ when compared to group $\mathrm{E}$.
Colonization of the gastrointestinal tract

S. Typhimurium SL1344nal ${ }^{\mathrm{r}}$ was not detected in the control groups that received PBS or Bimuno ${ }^{\circledR}$ alone. For the challenge groups, there was an overall trend of reduced numbers of $S$. Typhimurium in the ileum, colon and caecum when pre-dosed with Bimuno ${ }^{\circledR}$ (Fig. 3c, d, e). For the challenge groups, significantly less $S$. Typhimurium was noted in the ileum at 72 and $96 \mathrm{~h}$ post-challenge $[P=0.0006,95 \% \mathrm{CI}(-13.1,-3.78)$; and $0.0016,95 \%$ CI $(-13.1,-3.21)$, respectively], for the 
A

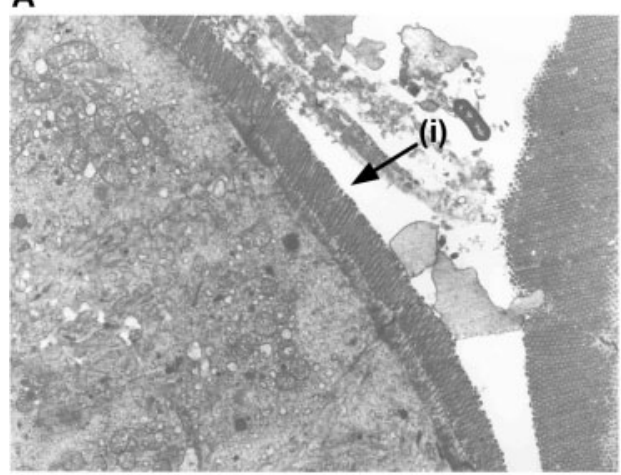

C

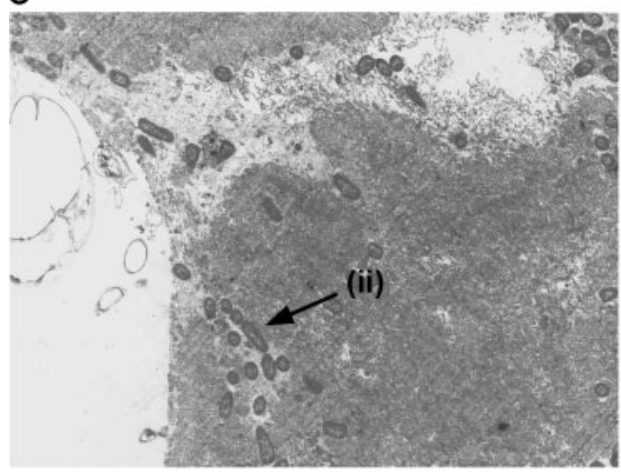

E

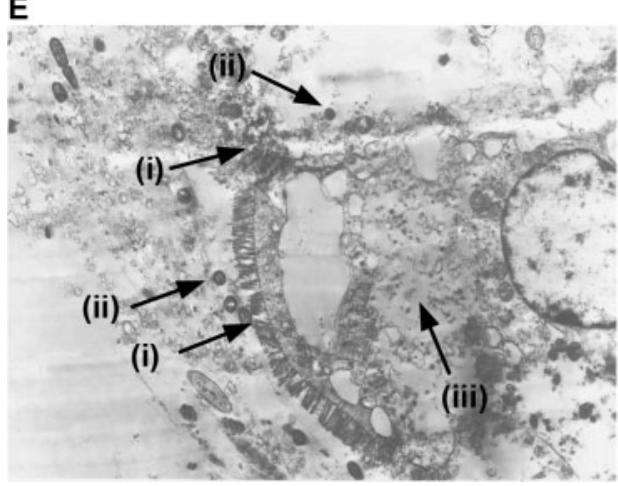

B

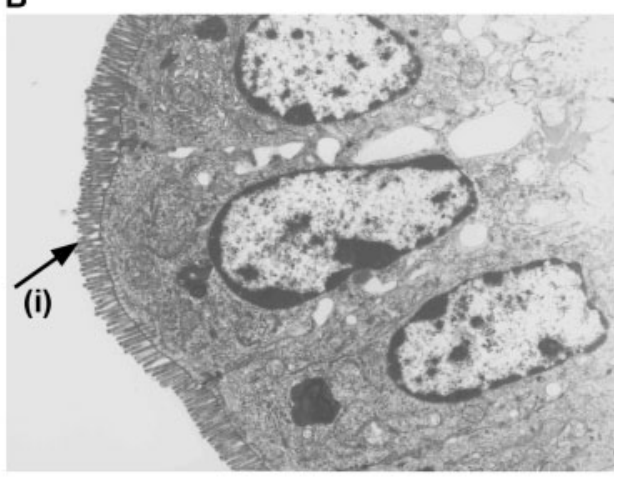

D

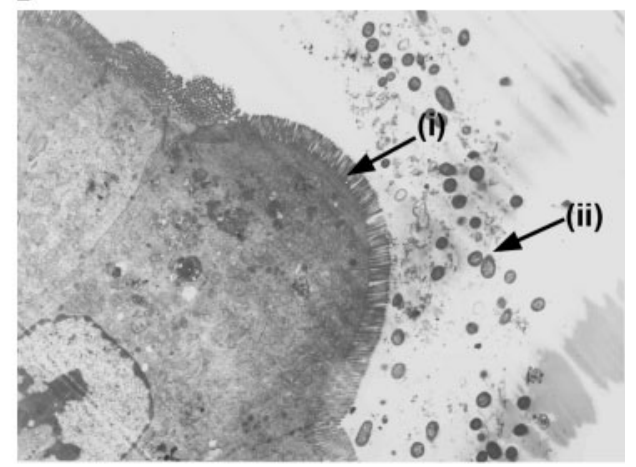

$\mathbf{F}$

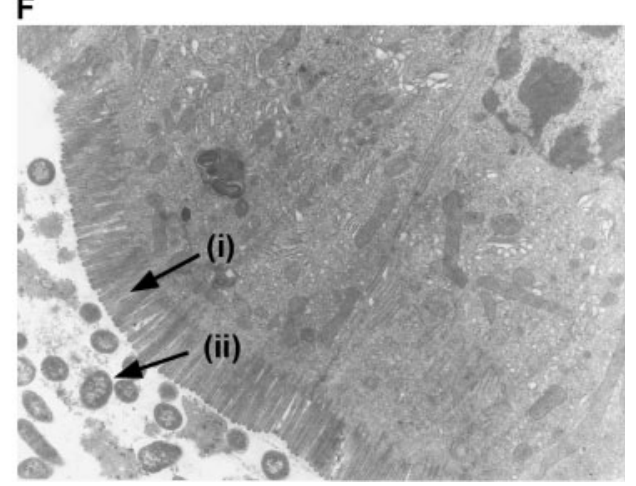

Fig. 2. Transmission electron microscopy of murine ligated ileal gut loops inoculated with $P B S$ ( $A ; 7.5 K$ magnification), Bimuno $^{\mathbb{R}}\left(\mathrm{B} ; 11.0 \mathrm{~K}\right.$ magnification), S. Typhimurium SL1344nal ${ }^{\mathrm{r}}$ (C; 11.0K magnification), SL1344nal ${ }^{\mathrm{r}}$ with Bimuno ${ }^{\mathbb{R}}$ (D; 7.5K magnification), S. Typhimurium LT2 (E; 7.4K magnification) and LT2 with Bimuno ${ }^{\mathbb{R}}$ (F; 13.0K magnification). Arrow (i) indicates the presence of brush borders, arrow (ii) indicates the presence of $S$. Typhimurium and arrow (iii) indicates the presence of a damaged cell, with bacterial invasion and loss of cell architecture. Loops A and B illustrate no cytopathic effects. Loops inoculated with $S$. Typhimurium alone ( $\mathrm{C}$ and $\mathrm{E}$ ) showed signs of bacterial adherence and invasion into the enterocytes and marked signs of pathology. Loops inoculated with Bimuno ${ }^{\mathbb{R}}$ and a Salmonella isolate (D and F) indicate that Bimuno ${ }^{\mathbb{R}}$ may protect the enterocytes from $S$. Typhimurium pathogenicity and invasion.

colon at $72 \mathrm{~h}$ post-inoculation $[P<0.0001,95 \% \mathrm{CI}$ $(-11.7,-4.64)]$ and for the caecum at 8,72 and $120 \mathrm{~h}$ post-inoculation $\quad[P=0.0099, \quad 95 \% \quad$ CI $\quad(1.29,9.13)$; $<0.0001,95 \% \mathrm{CI}(-12.9,-5.09)$; and $0.0002,95 \% \mathrm{CI}$ $(-11.5,-3.67)$, respectively] for the Bimuno ${ }^{\mathbb{R}}$ pre-treated group compared to the $S$. Typhimurium only challenged group (Fig. 3). With the exception of $8 \mathrm{~h}$ post-infection in the colon, there were no other significant differences between the two challenge groups. In the colon at $8 \mathrm{~h}$ post-infection, a significant increase in the recovery of $S$. Typhimurium was observed in the group pre-dosed with Bimuno ${ }^{\circledR}$ when compared to the $S$. Typhimurium only challenged group $[P=0.0171,95 \%$ CI $(0.79,7.86)]$ (Fig. $3 d)$. 
A

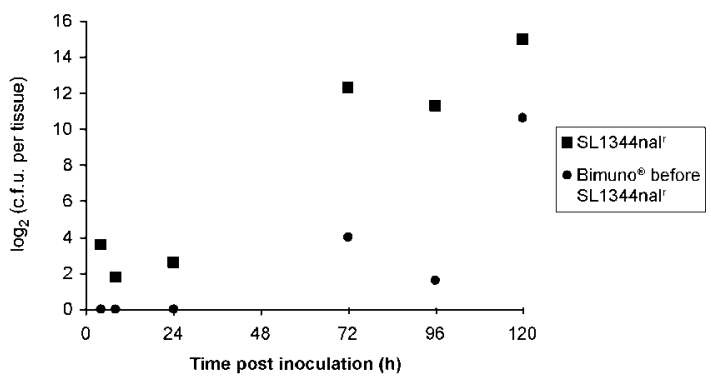

C

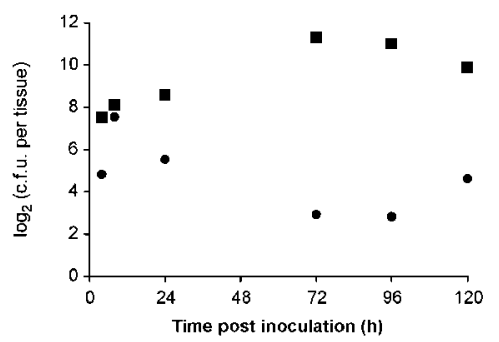

E

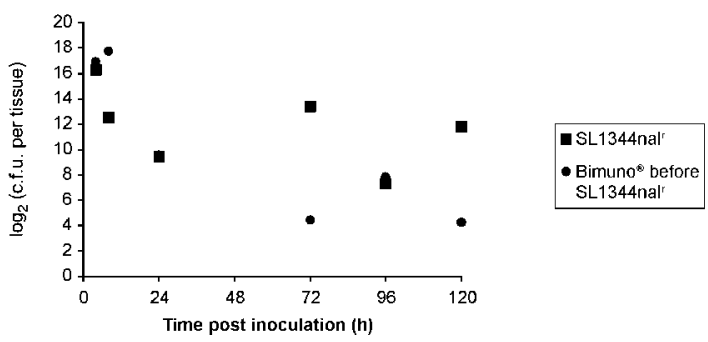

B

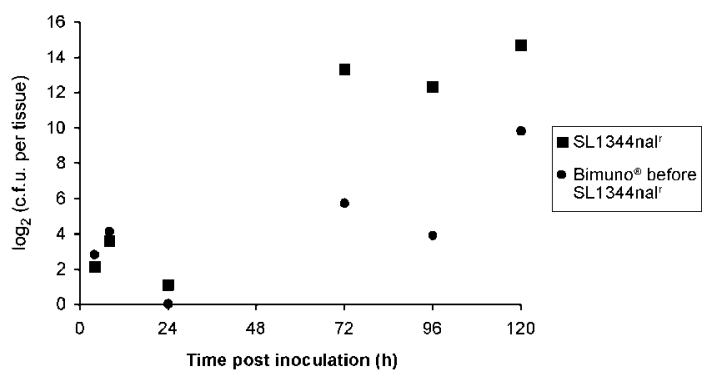

D

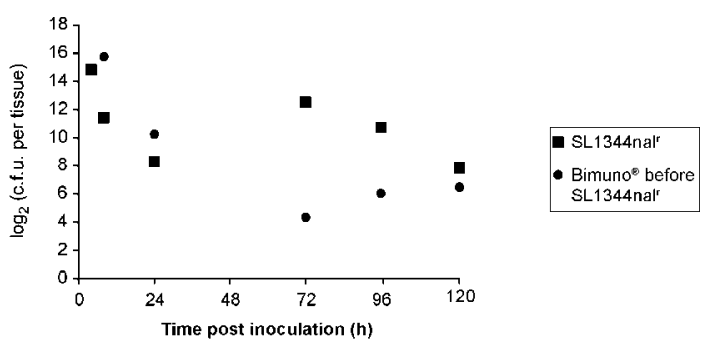

Fig. 3. Bacterial enumeration of $S$. Typhimurium SL1344nal (in trial 2) from the spleen (A), liver (B), ileum (C), colon (D) and caecum (E) of $B A L B / c$ mice in the presence or absence of Bimuno ${ }^{\mathbb{R}}$, group $F$ and $E$, respectively. Those samples positive only after enrichment were assigned an arbitrary value (between 10 and 50 c.f.u. per tissue) below the level of detection. Significant reductions in the recovery of SL1344nal ${ }^{r}$ were observed in all organs sampled when mice were pre-dosed with Bimuno ${ }^{\circledR}$ $(P<0.05)$. At all other time points, where mice were pre-dosed with Bimuno ${ }^{\circledR}$, the recovery of SL1344nal ${ }^{r}$ was similar to or lower than that in mice inoculated with SL1344nal'.

\section{Gross pathology}

No gross lesions were noted at necropsy for mice in control groups [PBS (C) and Bimuno ${ }^{\circledR}(\mathrm{D})$ ] or for mice pre-dosed with Bimuno ${ }^{\mathbb{R}}(\mathrm{F})$. Contrary to this, all mice in group $(\mathrm{E})$, which were challenged with $S$. Typhimurium alone, appeared dehydrated and displayed hepatomegaly and splenomegaly at 96 and $120 \mathrm{~h}$ post-challenge. Multifocal areas of hepatic necrosis were evident for all mice necropsied in group $\mathrm{E}$ at $120 \mathrm{~h}$ post-inoculation.

\section{Histopathology}

Histopathological examinations of the liver, spleen, ileum, caecum and colon were conducted (Tables 3 and 4). Tissues were well preserved; however, mucosal autolysis was observed in a small proportion of the intestinal tissues examined and some background changes were commonly noted, including lymphoid hyperplasia, submucosal oedema, red pulp hyperplasia of the spleen, and lifting (or sloughing) of musocal epithelium. Peri-portal inflammation was scrutinized and low numbers of scattered lymphocytes and neutrophils was considered a background level observation.

The results from trials 1 and 2 of the murine oral challenge studies indicated that the control groups dosed with PBS (C) or Bimuno ${ }^{\mathbb{R}}$ (D) were similar with most parameters recorded as within normal limits.

In trial 1 , the scoping experiment, there was a notable reduction in the number of lesions scored in the group pre- 
Table 3. Histopathological evaluation of the organs sampled upon serial necropsy from trial 1 of the murine oral challenge study

WNL, within normal limits; P, pyogranuloma. The study contained five mice per group.

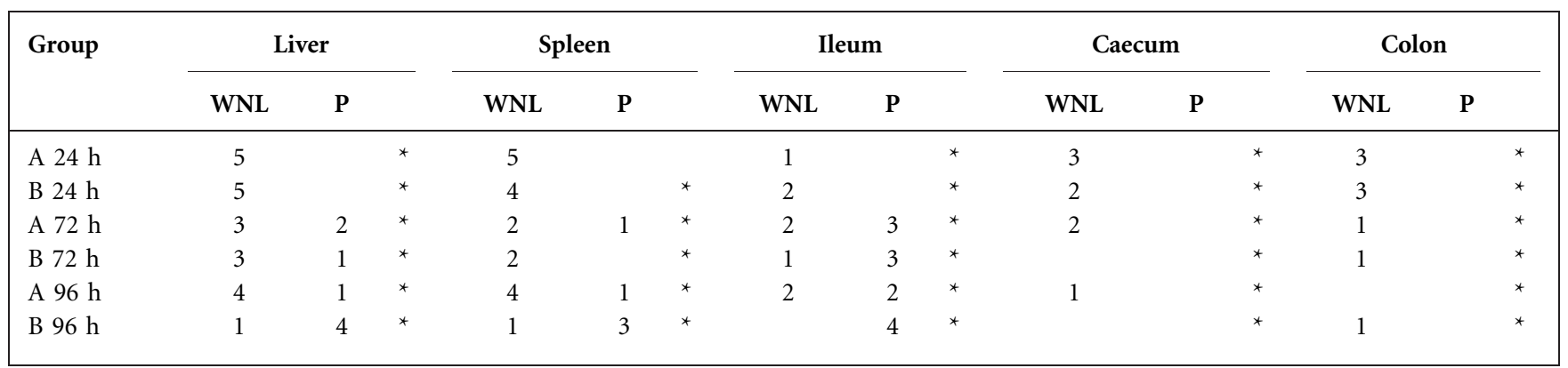

${ }^{\star}$ Indicates that tissue segments contained lymphoid hyperplasia, submucosal oedema, portal inflammation, autolysis or other histological change.

dosed with Bimuno ${ }^{\circledR}$ before challenge with $S$. Typhimurium (B) when compared to the group dosed with $S$. Typhimurium alone (A) (Table 3). Specifically, at $72 \mathrm{~h}, 2 / 5$ of the mice dosed with $S$. Typhimurium alone (A) had pyogranulomas in the liver compared to $1 / 5$ in the group pre-dosed with Bimuno ${ }^{\circledR}(\mathrm{B})$. This same trend was seen in the spleen, where $1 / 5$ of the mice in group $A$ had pyogranulomas compared to $0 / 5$ in group $\mathrm{B}$ (Table 3 ).
In trial 2, the number of lesions scored and their severity were generally reduced in the group pre-dosed with Bimuno $^{\circledR}$ (F) when compared to the group challenged with $S$. Typhimurium alone (E) (Table 4). This was most evident at 72, 96 and $120 \mathrm{~h}$ post Salmonella challenge. Specifically, at $96 \mathrm{~h}$ post-challenge, $4 / 4$ of mice challenged with $S$. Typhimurium alone (E) had pyogranulomas in the liver and spleen above normal limits compared to $1 / 5$ in

Table 4. Histopathological evaluation of the organs sampled upon serial necropsy from trial 2 of the murine oral challenge study

WNL, within normal limits; P, pyogranuloma. The study contained five mice per group (unless otherwise stated).

\begin{tabular}{|c|c|c|c|c|c|c|c|c|c|c|c|c|c|c|}
\hline \multirow[t]{2}{*}{ Group } & \multicolumn{3}{|c|}{ Liver } & \multicolumn{3}{|c|}{ Spleen } & \multicolumn{3}{|c|}{ Ileum } & \multicolumn{3}{|c|}{ Caecum } & \multicolumn{2}{|c|}{ Colon } \\
\hline & WNL & $\mathbf{P}$ & & WNL & $\mathbf{P}$ & & WNL & $\mathbf{P}$ & & WNL & $\mathbf{P}$ & & WNL & $\mathbf{P}$ \\
\hline D $4 \mathrm{~h}$ & 5 & & & 5 & & & 3 & & * & 3 & & * & 3 & * \\
\hline E $4 \mathrm{~h}$ & 5 & & * & 5 & & & & & * & 1 & & * & 4 & * \\
\hline F $4 \mathrm{~h}$ & 2 & & * & 3 & & * & 1 & & * & & & * & 4 & * \\
\hline E $8 \mathrm{~h}$ & 5 & & * & 5 & & * & 1 & & * & 2 & & * & 5 & \\
\hline F $8 \mathrm{~h}$ & 4 & & * & 4 & & * & 2 & & * & 4 & & * & $4 / 4$ & \\
\hline C $24 \mathrm{~h}$ & 5 & & & 5 & & * & 4 & & * & 2 & & * & 5 & * \\
\hline D $24 \mathrm{~h}$ & 5 & & * & 5 & & * & & & * & & & * & 5 & * \\
\hline E $24 \mathrm{~h}$ & 5 & & & 5 & & * & 4 & & * & 2 & & * & 4 & * \\
\hline F $72 \mathrm{~h}$ & 2 & 2 & * & 4 & 1 & * & 3 & 1 & * & 1 & & * & 5 & * \\
\hline C $96 \mathrm{~h}$ & 5 & & * & 5 & & * & 2 & & * & 2 & & * & 4 & * \\
\hline D $96 \mathrm{~h}$ & 5 & & & 5 & & & 3 & & * & 2 & & * & 5 & \\
\hline E $96 \mathrm{~h}$ & & $4 / 4$ & & & $4 / 4$ & & $2 / 4$ & $1 / 4$ & * & $3 / 4$ & & * & $3 / 3$ & \\
\hline F $96 \mathrm{~h}$ & 4 & 1 & * & 4 & 1 & * & 3 & 1 & * & & & * & 4 & * \\
\hline C $120 \mathrm{~h}$ & 5 & & * & 5 & & * & 3 & & * & 1 & & * & 4 & * \\
\hline $\mathrm{D} 120 \mathrm{~h}$ & 5 & & & 5 & & * & 4 & & * & 3 & & * & 5 & \\
\hline E $120 \mathrm{~h}$ & 1 & 5 & & 1 & 4 & & 2 & 1 & * & 4 & 1 & & 5 & \\
\hline F $120 \mathrm{~h}$ & 1 & 4 & * & & 3 & & 3 & 2 & & 1 & & * & 5 & \\
\hline
\end{tabular}

${ }^{\star}$ Indicates that tissue segments contained lymphoid hyperplasia, submucosal oedema, portal inflammation, autolysis or other histological change. 
the Bimuno ${ }^{\circledR}$ pre-treated group (F) (Table 4). Similarly at $72 \mathrm{~h}$ post-infection, $3 / 5$ of mice challenged with $S$. Typhimurium alone (E) had pyogranulomas in the spleen compared to $1 / 5$ in the Bimuno ${ }^{\mathbb{R}}$ pre-treated group (F) (Table 4). In both trials, an overall pattern of decreased pathology was observed; however, some variation was seen where some groups showed an increase in the number of lesions; i.e. at $72 \mathrm{~h}$ in the ileum, $0 / 5$ of group $\mathrm{E}$ had pyogranulomas compared to $1 / 5$ of group $\mathrm{F}$ (Table 4). A small proportion of the tissues did not meet the required standard for accurate microscopical interpretation and thus were excluded from the study.

\section{DISCUSSION}

In this study, appropriate in vitro and in vivo models were utilized to evaluate the efficacy of Bimuno ${ }^{\mathbb{R}}$ in mitigating against the adherence and invasion of $S$. Typhimurium and the pathology associated with murine salmonellosis. The results from the oral mouse model indicate that Bimuno ${ }^{\mathbb{R}}$ suppressed the ability of $S$. Typhimurium to colonize and cause associated pathology. Oral administration of Bimuno $^{\mathbb{R}}$ to $\mathrm{BALB} / \mathrm{c}$ mice immediately prior to $S$. Typhimurium challenge resulted in reductions in all clinical signs and statistically significant reductions in the number of $S$. Typhimurium colonizing the various tissues examined and subsequently reduced the pathology associated with salmonellosis. It is reasonable to conclude that Bimuno ${ }^{\circledR}$ has a protective role in the murine model.

With regard to the possible mechanism of protection, clues may be obtained from the reductions in invasion to mucus-secreting human colonic enterocytes (HT-29-16E) and protection from $S$. Typhimurium-induced gut pathology in murine ligated ileal gut loops in the presence of Bimuno ${ }^{\mathbb{R}}$. Tissue culture assays showed significant reductions in invasion of $S$. Typhimurium, even at $\sim 2 \mathrm{mM}$ concentrations, to the mucus-secreting cell type ( $P$ $<0.0001)$. This cell type may be more representative of the enterocytes in the gastrointestinal tract. No significant differences in bacterial adherence were observed at this concentration; however, significant increases in the adherence of $S$. Typhimurium were observed in all instances where $20 \mathrm{mM}$ Bimuno ${ }^{\mathbb{R}}$ was applied in combination with the bacterial isolates. It is possible that Bimuno ${ }^{\mathbb{R}}$ may be blocking the invasion of the bacteria, possibly by acting as a receptor mimic. Receptor mimicry has previously been suggested in the literature (Schnaar, 1991; Gibson et al., 2005; Shoaf et al., 2006); the prebiotic may be binding specific receptors on the host epithelial cell surface, thus blocking the adherence and subsequent invasion of $S$. Typhimurium. Alternatively, Bimuno ${ }^{\mathbb{R}}$ may be having a direct effect on the host, i.e. it may affect mucus viscosity or induce a refractory response in the host to prevent bacterial invasion. Previously published data indicate that Bimuno ${ }^{\mathbb{R}}$ causes significant reductions in the association of $S$. Typhimurium and enteropathogenic E. coli to HT-29 cells (Tzortzis et al., 2005b). This, together with the data presented here, indicates that Bimuno ${ }^{\circledR}$ may have a dosedependent effect on the adherence of the pathogen and its efficacy in reducing the invasion of the pathogen is dependent on the dose of Bimuno ${ }^{\circledR}$ and the bacterial strain. Further investigations are required to analyse the effect of Bimuno ${ }^{\mathbb{R}}$ on a wider range of eukaryotic host cell types and bacterial isolates.

Furthermore, the murine ligated ileal gut loop studies clearly indicated that Bimuno ${ }^{\mathbb{R}}$ suppressed the attachment, invasion and associated pathology of $S$. Typhimurium to the enterocytes immediately (Figs 1 and 2) despite there being abundant numbers of bacteria in the lumen. The same level of protection was not afforded in tissue culture assays; this may be due to the artificial nature of tissue culture. Furthermore, mucoid and blood-stained gut loop contents, associated with the pathology caused by salmonellosis, were not observed in the presence of Bimuno ${ }^{\circledR}$. The gut loop results may be more representative of the true effect of Bimuno ${ }^{\mathbb{R}}$ on the murine host; the model allows for intimate host-microbe interactions to be monitored in real-time and allows for superior tissue quality. It may be of interest to use this well-established model (Smith \& Halls, 1967; Meyerholz et al., 2002; Wales et al., 2002; Girard et al., 2008) to study whether protection could be conferred against a wider range of gastrointestinal pathogens.

A number of other key issues arise from these studies; specifically, Bimuno ${ }^{\circledR}$, at the doses used, does not have a cytotoxic effect on the eukaryotic host. No cytopathic effect was observed on HT-29 cells and, furthermore, no clinical signs or gross histopathology were noted for either the gut loop studies or oral challenge studies (Figs 1 and 2 and Table 4). As it is widely known to be atoxic, Bimuno ${ }^{\mathbb{R}}$ may be useful in preventing diarrhoea, e.g. travellers' diarrhoea, in humans. Oral dosing of $2500 \mathrm{mg}$ GOS $\mathrm{kg}^{-1}$ has previously been shown to not be toxic when administered to rats over a 90 day period (Anthony et al., 2006), a finding which is supported here, thus this dose was used throughout the in vivo murine oral challenge studies. The mice were dosed with Bimuno ${ }^{\mathbb{R}} \sim 30 \mathrm{~min}$ prior to Salmonella challenge for practical reasons and to allow time for the prebiotic mixture to reach the gastrointestinal tract ahead of the Salmonella.

Bimuno ${ }^{\circledR}$ significantly reduces the colonization of $S$. Typhimurium in vivo in the $\mathrm{BALB} / \mathrm{c}$ mouse model, a model that has been used extensively to characterize enteropathogens (Dunlap et al., 1991; Santos et al., 2001), and the use of $S$. Typhimurium in this model is regarded as an effective surrogate model of Salmonella Typhi infection in humans (Santos et al., 2001). Bimuno ${ }^{\mathbb{R}}$ significantly reduced the colonization of $S$. Typhimurium in all organs, across all time points sampled, in the in vivo oral challenge study (Fig. 3). This indicates that the initial suppressive effects conferred by Bimuno ${ }^{\mathbb{R}}$ were lasting. A single bolus of Bimuno ${ }^{\circledR}\left(2500 \mathrm{mg} \mathrm{kg}^{-1}\right)$, administered by oral gavage $\sim 30 \mathrm{~min}$ prior to $S$. Typhimurium challenge, 
was sufficient to suppress its colonization and subsequent clinical signs (such as ruffled fur, dehydration and prostration) throughout the $120 \mathrm{~h}$ sampling period. It would be of interest to follow the infection beyond the $120 \mathrm{~h}$ time point to see whether group F developed the clinical symptoms observed in group E. However, for ethical reasons, this was not plausible. Murine challenges with $S$. Typhimurium SL1344nal ${ }^{\mathrm{r}}$ were terminated at $120 \mathrm{~h}$ post-challenge to reduce the severity of the studies, as this isolate can lead to $100 \%$ mortality after this time period. Throughout the sampling period, the recovery of $S$. Typhimurium when predosed with Bimuno ${ }^{\mathbb{R}}$ was similar to or lower than that of the Salmonella control group. The only exception was in the colon at $8 \mathrm{~h}$ where the recovery was significantly higher in group $\mathrm{F}$ compared to group $\mathrm{E}$. This may be due to experimental error or alternatively may be due to Bimuno ${ }^{\circledR}$ reducing the invasion of $S$. Typhimurium in the early stages of infection, therefore leading to retention of $S$. Typhimurium in the lower gastrointestinal tract. The pathology induced by salmonellosis was generally reduced in groups pre-dosed with Bimuno ${ }^{\mathbb{R}}(\mathrm{F})$. Pre-dosing with Bimuno ${ }^{\mathbb{R}}$ was associated with diminished pyogranulomas in the liver and spleen (Table 4). Some variation was observed and may be attributed to individual differences between mice. Shedding of $S$. Typhimurium was also markedly reduced by $120 \mathrm{~h}$ post-challenge in the group pre-dosed with Bimuno ${ }^{\circledR}$, which may indicate a protective effect conferred by Bimuno ${ }^{\circledR}$.

In infections, Salmonella colonizes the gastrointestinal tract of the mouse and then traverses the ileal Peyer's patches to induce a systemic infection. The results presented here demonstrate that Bimuno ${ }^{\circledR}$ was protecting against Salmonella in both the gastrointestinal and systemic phases of infection. However, further investigations are required to study the longevity of the effect of Bimuno ${ }^{\mathbb{R}}$, to assess whether the suppression of invasion is sufficient to reduce the systemic effects, to optimize the pre-dose incubation time and to test the efficacy of Bimuno ${ }^{\mathbb{R}}$ at reducing the invasion of a wider range of gastrointestinal pathogens in a broader range of animal models.

The experimental results presented within this study are in agreement that $S$. Typhimurium-induced pathology and invasion is suppressed in the presence of Bimuno ${ }^{\circledR}$. Prebiotics have been implicated in providing the host with enhanced resistance to zoonotic pathogens which cause gastroenteritis (Gibson et al., 2005). The exact mechanisms of action by which prebiotics, such as GOS, mitigate infection are still to be elucidated. However, it is evident from the studies conducted here that a reduction in adherence to the gut mucosa may play an important role in preventing or delaying subsequent invasion. The protective effect was not tested using other types of GOS and therefore direct comparisons between GOS preparations cannot be made.

It is plausible that the GOS in Bimuno ${ }^{\circledR}$ may exclude $S$. Typhimurium from the gut, possibly by actively binding to it, thus promoting bacterial clearance from the gastro- intestinal tract. If this is the case, it may not only be working as a prebiotic but also may directly affect the pathogen. Alternatively, it may be that Bimuno $^{\circledR}$ is modulating the normal gut flora to allow competitive exclusion of pathogens (Bailey et al., 1991; SmirickyTjardes et al., 2003). Human milk oligosaccharides have been implicated in directly and indirectly stimulating the immune response of the host, indirectly by stimulating the normal flora to proliferate and directly through interactions with immune cells (Arslanoglu et al., 2007). This may also be the case for Bimuno ${ }^{\mathbb{R}}$, that it primes the immune response of the host to allow more effective clearance of pathogens (Agunos et al., 2007).

Collectively, the studies presented here clearly indicate that Bimuno ${ }^{\mathbb{R}}$ reduces the severity of salmonellosis and associated pathology when assessed in a mouse model of infection. However, further studies are required to elucidate the exact mechanisms of its action.

\section{ACKNOWLEDGEMENTS}

The authors acknowledge Clasado Ltd for supplying the test substance, Bimuno ${ }^{\mathbb{R}}$, Emma Kennedy for technical support in the laboratory, and members of the Animal Service Unit (ASU) for their technical support with in vivo studies. We acknowledge Bentley Crudgington for assisting with the histopathology and the Cell and Tissue Culture Section at VLA (Weybridge) for preparing the HT-29 cells. Finally, we acknowledge Glenn Gibson and Robert Rastall (University of Reading) for their continued support. This study was funded through Clasado Ltd, project FT1303.

\section{REFERENCES}

Agunos, A., Ibuki, M., Yokomizo, F. \& Mine, Y. (2007). Effect of dietary $\beta 1-4$ mannobiose in the prevention of Salmonella enteritidis infection in broilers. Br Poult Sci 48, 331-341.

Anthony, J. C., Merriman, T. N. \& Heimbach, J. T. (2006). 90-Day oral (gavage) study in rats with galactooligosaccharides syrup. Food Chem Toxicol 44, 819-826.

Arslanoglu, S., Moro, G. \& Boehm, G. (2007). Early supplementation of prebiotic oligosaccharides protects formula-fed infants against infections during the first 6 months of life. J Nutr 137, 2420-2424.

Bailey, J. S., Blankenship, L. C. \& Cox, N. A. (1991). Effect of fructooligosaccharide on Salmonella colonization of the chicken intestine. Poult Sci 70, 2433-2438.

Boehm, G., Jelinek, J., Stahl, B., van Laere, K., Knol, J., Fanaro, S., Moro, G. \& Vigi, V. (2004). Prebiotics in infant formulas. J Clin Gastroenterol 38, S76-S79.

Carlson, S. A., Stoffregen, W. C. \& Bolin, S. R. (2002). Abomasitis associated with multiple antibiotic resistant Salmonella enterica serotype Typhimurium phagetype DT104. Vet Microbiol 85, 233-240.

Castanon, J. I. (2007). History of the use of antibiotic as growth promoters in European poultry feeds. Poult Sci 86, 2466-2471.

Collins, M. D. \& Gibson, G. R. (1999). Probiotics, prebiotics and synbiotics: approaches for modulating the microbial ecology of the gut. Am J Clin Nutr 69, 1052S-1057S.

Coppa, G. V., Bruni, S., Morelli, L., Soldi, S. \& Gabrielli, O. (2004). The first prebiotics in humans: human milk oligosaccharides. J Clin Gastroenterol 38, S80-S83. 
Depeint, F., Tzortzis, G., Vulevic, J., l'Anson, K. \& Gibson, G. R. (2008). Prebiotic evaluation of a novel galactooligosaccharide mixture produced by the enzymatic activity of Bifidobacterium bifidum $N C I M B$ 41171, in healthy humans: a randomized, double-blind, crossover, placebo-controlled intervention study. Am J Clin Nutr 87, 785-791.

Dunlap, N. E., Benjamin, W. H., Jr, McCall, R. D., Jr, Tilden, A. B. \& Briles, D. E. (1991). A 'safe-site' for Salmonella typhimurium is within splenic cells during the early phase of infection in mice. Microb Pathog 10, 297-310.

Gibson, G. R. \& Roberfroid, M. B. (1995). Dietary modulation of the human colonic microbiota: introducing the concept of prebiotics. J Nutr 125, 1401-1412.

Gibson, G. R., McCartney, A. L. \& Rastall, R. A. (2005). Prebiotics and resistance to gastrointestinal infections. Br J Nutr 93, S31-S34.

Girard, F., Frankel, G., Phillips, A. D., Cooley, W., Weyer, U., Dugdale, A. H. A., Woodward, M. J. \& La Ragione, R. M. (2008). Interaction of enterohemorrhagic Escherichia coli O157:H7 with mouse intestinal mucosa. FEMS Microbiol Lett 283, 196-202.

Hald, T. (2001). Salmonella in pork - epidemiology, control and the public health impact. $\mathrm{PhD}$ thesis, Royal Veterinary and Agricultural University, Copenhagen, Denmark.

Ito, Y., Moriwaki, H., Muto, Y., Kato, N., Watanabe, K. \& Ueno, K. (1997). Effect of lactulose on short-chain fatty acids and lactate production and on the growth of faecal flora, with special reference to Clostridium difficile. J Med Microbiol 46, 80-84.

La Ragione, R. M., Best, A., Clifford, D., Weyer, U., Johnson, L., Marshall, R. N., Marshall, J., Cooley, W. A., Farrelly, S. \& other authors (2006). Influence of colostrum deprivation and concurrent Cryptosporidium parvum infection on the colonization and persistence of Escherichia coli O157 : H7 in young lambs. J Med Microbiol 55, 819828.

Meyerholz, D. K., Stabel, T. J., Ackermann, M. R., Carlson, S. A., Jones, B. D. \& Pohlenz, J. (2002). Early epithelial invasion by Salmonella enterica Serovar Typhimurium DT104 in the swine ileum. Vet Pathol 39, 712-720.

Rabiu, B. A., Jay, A. J., Gibson, G. R. \& Rastall, R. A. (2001). Synthesis and fermentation properties of novel galacto-oligosaccharides by $\beta$-galactosidases from Bifidobacterium species. Appl Environ Microbiol 67, 2526-2530.

Sako, T., Matsumoto, K. \& Tanaka, R. (1999). Recent progress on research and applications of non-digestible galacto-oligosaccharides. Int Dairy J 9, 69-80.

Santos, R. L., Zhang, S., Tsolis, R. M., Kingsley, R. A., Adams, L. G. \& Bäumler, A. J. (2001). Animal models of Salmonella infections: enteritis versus typhoid fever. Microbes Infect 3, 1335-1344.

Schnaar, R. L. (1991). Glycosphingolipids in cell surface recognition. Glycobiology 1, 477-485.

Shoaf, K., Mulvey, G. L., Armstrong, G. D. \& Hutkins, R. W. (2006). Prebiotic galactooligosaccharides reduce adherence of enteropathogenic Escherichia coli to tissue culture cells. Infect Immun 74, 69206928.

Smiricky-Tjardes, M. R., Grieshop, C. M., Flickinger, E. A., Bauer, L. L. \& Fahey, G. C., Jr (2003). Dietary galactooligosaccharides affect ileal and total-tract nutrient digestibility, ileal and fecal bacterial concentrations, and ileal fermentative characteristics of growing pigs. J Anim Sci 81, 2535-2545.

Smith, H. W. \& Halls, S. (1967). Observations by the ligated intestinal segment and oral inoculation methods on Escherichia coli infections in pigs, calves, lambs and rabbits. J Pathol Bacteriol 93, 499-529.

Tzortzis, G., Goulas, A. K. \& Gibson, G. R. (2005a). Synthesis of prebiotic galactooligosaccharides using whole cells of a novel strain, Bifidobacterium bifidum NCIMB 4117. Appl Microbiol Biotechnol 68, 412-416.

Tzortzis, G., Goulas, A. K., Gee, J. M. \& Gibson, G. R. (2005b). A novel galactooligosaccharide mixture increases the bifidobacterial population numbers in a continuous in vitro fermentation system and in the proximal colonic contents of pigs in vivo. J Nutr 135, 1726-1731.

Wales, A. D., Clifton-Hadley, F. A., Cookson, A. L., Dibb-Fuller, M. P., La Ragione, R. M., Pearson, G. R. \& Woodward, M. J. (2002). Production of attaching-effacing lesions in ligated large intestine loops of 6-month-old sheep by Escherichia coli O157:H7. J Med Microbiol 51, 755-763.

WHO (2005). Drug-resistant Salmonella. Geneva: World Health Organization. 